\title{
Presolar graphite in meteorites - H.C. Urey Medal Lecture
}

\section{SACHIKO AMARI}

\author{
Washington University in St. Louis
}

Presenting Author: sa@physics.wustl.edu

Presolar grains are stardust formed in the stellar outflow or ejecta, and remained mostly intact in primitive meteorites and other extra-terrestrial materials throughout the journey to Earth. The study of presolar grains helps us better understand nucleosynthesis in stars and mixing in stellar ejecta and outflow, and has opened a new field of astronomy.

Mineral types of presolar grains include diamond, SiC, graphite, oxides, silicates and refractory carbides. Presolar graphite carries a ${ }^{22} \mathrm{Ne}$-rich component, $\mathrm{Ne}-\mathrm{E}(\mathrm{L})$, and shows a range of density $\left(1.6-2.2 \mathrm{~g} / \mathrm{cm}^{3}\right)$. One of the most intriguing features of presolar graphite is that isotopic and morphological features depend on density [1-3].

Many low-density graphite grains $\left(1.6 \sim 2.10 \mathrm{~g} / \mathrm{cm}^{3}\right)$ show ${ }^{15} \mathrm{~N}$ and ${ }^{18} \mathrm{O}$ excesses, high ${ }^{26} \mathrm{Al} /{ }^{27} \mathrm{Al}$ ratios (up to 0.69 ), $\mathrm{Si}$ isotopic anomalies $\left({ }^{28} \mathrm{Si}\right.$ excess in many cases, ${ }^{29,30} \mathrm{Si}$ excesses in some cases), and the initial presence of ${ }^{44} \mathrm{Ti}\left(\mathrm{T}_{1 / 2}=60 \mathrm{a}\right)$ in the form of ${ }^{44} \mathrm{Ca}$ excesses. These isotopic signatures of low-density graphite grains are similar to those of $\mathrm{SiC} \mathrm{X}$ grains and both of them are considered to have originated from supernovae.

A significant portion of high-density graphite grains in both Murchison (CM2) and Orgueil (CI) were produced in asymptotic giant branch (AGB) stars with low-metallicity. However, highdensity grains of supernova origin are much more abundant in Orgueil than in Murchison. Also, a few high-density Orgueil grains with low ${ }^{12} \mathrm{C} /{ }^{13} \mathrm{C}$ ratios $\left(9 \sim 18,{ }^{12} \mathrm{C} /{ }^{13} \mathrm{C}_{\text {solar }}=89\right)$ and extremely high $\mathrm{Ca}$ and $\mathrm{Ti}$ excesses most likely formed in postasymptotic giant branch stars that had suffered a very late thermal pulse.

References: [1] Hoppe P. et al. (1995) Geochim. Cosmochim. Acta, 59, 4029-4056. [2] Jadhav M. et al. (2013) Geochem. Cosmochim. Acta, 113, 193-224. [3] Amari S. et al. (2014) Geochem. Cosmochim. Acta, 133, 479-522. 